\title{
VARIEDADES
}

\section{POR QUÉ ‘ABD AL-RAHMĀN III SUCEDIÓ A SU ABUELO EL EMIR 'ABD ALLĀH ${ }^{1}$}

\author{
MARIBEL FIERRO \\ Instituto de Filología, CSIC, Madrid
}

El primer califa omeya de al-Andalus, 'Abd al-Rahmān III (r. 300/912-350/961), se llamaba Abū l-Muțarrif 'Abd al-Rahmān b. Muhammad b. 'Abd Allāh b. Muḥammad b. 'Abd al-Raḥmān II b. al-Ḥakam b. Hišām b. 'Abd al-Raḥmān I. Tanto el nombre (ism 'alam) como la kunya son reveladores de las circunstancias en las que se re-construyó la legitimidad omeya durante la época que precedió al acceso de 'Abd al-Raḥmān III al trono.

Algunos de los investigadores que se han ocupado de la biografía de 'Abd al-Rahmān III se han sorprendido de que llevase la kunya de Abū l-Mutarrif, dado que no se sabe que tuviese ningún hijo con ese nombre, en cuyo caso se habría tratado de una kunya de filiación paterna («padre de Muțarrif») ${ }^{2}$, y dado que Muțarrif era el nombre del asesino de Muhammad, el padre de 'Abd al-Rahmmān III. El asesinato parece haber sido cometido por instigación del propio emir 'Abd Allāh (r. 275/888-300/912). Éste, en efecto, había hecho encarcelar a su hijo Muhammad (el emir 'Abd Allāh era el abuelo de 'Abd al-Rahmān III), en el año 277/891, el mismo año del nacimiento de 'Abd al-Rahmān. El emir 'Abd Allāh parece haber temido que su hijo Muhammad (el primogénito al que había nombrado heredero) estuviese conspirando contra él, tal vez en conexión con la presencia por aquel entonces de Ibn Hafșūn en las cercanías de Córdoba. Habiendo sido puesto en liber-

\footnotetext{
1 Lo que aquí desarrollo está ya apuntado en mi libro 'Abd al-Rahman III, the first Cordoban caliph, Oneworld, 2005, 39. Agradezco a Julio Escalona y Luis Molina sus útiles comentarios, así como a Eduardo Manzano sus sugerencias.

2 Vallvé, J., Abderramán III. Califa de España y Occidente (912-961), Barcelona, 2003, 20, piensa que 'Abd al-Rạ̣mān III adoptó esa kunya por el significado del nombre Mutarrif («aquél del que se espera que sea un campeón, un caballero en las lides de la guerra, como Servidor de Dios»).
}

Al-Qanțara XXVI, 2 (2005) 357-369 
tad o a punto de ser puesto en libertad, Muhammad fue asesinado por su hermano (no uterino) Mutarrif, quien lo golpeó hasta causarle la muerte ${ }^{3}$. El emir no castigó a Mutarrif por este crimen, antes bien justificó el asesinato esgrimiento la desobediencia y rebeldía de Muhammad. Las mismas acusaciones pesaron luego sobre Mutarrif, a quien unos años más tarde, en 282/895, el emir 'Abd Allāh ordenó ejecutar temiendo que se hubiese aliado con los rebeldes sevillanos. Muṭarrif fue también acusado de beber vino e incluso de zandaqa, término que designa la apostasía encubierta, no declarada, y más en general la herejía. Esta última acusación ${ }^{4}$ es desarrollada en una crónica, la de Ibn al-Qūtiyya, compuesta en la primera mitad del s. IV/X por un leal servidor del califa omeya ${ }^{5}$, en lo que parece claramente un relato destinado a presentar la figura de Mutarrif de una manera totalmente negativa.

Por todo ello, podríamos sorprendernos de que 'Abd al-Raḥmān III llevase una kunya basada en el nombre del asesino de su padre. Cabría entonces preguntarse si lo pudo adoptar de forma simbólica, como una manera de indicar que no olvidaba lo que le había ocurrido a su padre: la incorporación del nombre del asesino al suyo podría entenderse como una forma de adueñarse de él, a modo de una venganza póstuma. Pero el simbolismo pudo haber ido en sentido contrario, indicando con su nombre (Abū l-Muṭarrif 'Abd al-Raḥmān b. Muhammad) que asumía la herencia tanto de su padre como de su tío y emitiendo así el mensaje de que la familia omeya estaba unida y debía permanecer unida, que las matanzas internas debían terminar y que él, empeñado en

${ }^{3}$ Sobre estos acontecimientos véanse Ibn al-Qūtiyya, Ta'rỉj iftitāh al-Andalus, ed. y trad. J. Ribera, Madrid, 1926, 106/90; Ibn Hazm, Naqt al-'arūs, ed. C. F. Seybold, trad. L. Seco de Lucena, Valencia, 1974, 166/114 y 173/132; Ibn Hayyān, al-Muqtabis, ed. M. Antuña, París, 1937, 41, 114; Ibn 'Id̄ārī, al-Bayān al-mugrib, ed. G. S. Colin y É. Lévi-Provençal, 2 vols., Leiden, 1948-1951 (trad. E. Fagnan, basada en la edición de R. Dozy, 2 vols., Argel, 1901-4), II, 154-5/248-50 y 160-1/258; Dikr biläd al-Andalus, ed. y trad. L. Molina, 2 vols., Madrid, 1983, 129-30/165; Ibn al-Jațīb, al-Ihāța fi ajbār Garnāta, ed. 'A. 'Inān, 4 vols., El Cairo, 1393/1973-1397/1977, III, 278-80; Dozy, R., «Introduction au Bayān», en Histoire de l'Afrique et de l'Espagne (ed. de al-Bayān al-mugrib), 2 vols., Leiden, 1848-1851, 40-61; Lévi-Provençal, E., Histoire de l'Espagne musulmane, 3 vols., París-Leiden, 1950-1953, I, 334-5; Makki, M. 'A., Ensayo sobre las aportaciones orientales en la España musulmana y su influencia en la formación de la cultura hispano-árabe, Madrid, 1968, 217, nota 3.

4 Véase al respecto Fierro, M. I., La heterodoxia en al-Andalus durante el periodo omeya, Madrid, 1987, 101-6.

5 V. al respecto Fierro, M., «La obra histórica de Ibn al-Qūṭiyya», Al-Qanțara X (1989), 485-512; Martínez-Gros, G., L'idéologie omeyyade. La construction de la légitimité du Califat de Cordoue (Xe-XIe siècles), Madrid, 1992, 50-112. 
devolver el esplendor y el poder de antaño a la dinastía tras la grave crisis del emirato de su abuelo, velaría para que no hubiese desunión. Veremos en seguida que ninguna de estas posibles interpretaciones puede ser admitida y que la razón de que 'Abd al-Raḥmān III llevase la kunya «Abū l-Muțarrif» es muy sencilla. Pero la discusión sobre estas posibles razones sirve para iluminar algunos aspectos clave del contexto que hizo posible que 'Abd al-Raḥmān III accediese al emirato.

Cuando 'Abd al-Raḥmān III fue nombrado emir (año 300/912), los omeyas andalusíes atravesaban el peor momento de su historia. Las rebeliones de árabes, muladíes y beréberes de la segunda mitad del s. III/IX (lo que se conoce como la fitna) habían reducido considerablemente el territorio de al-Andalus bajo su control y el establecimiento del califato fatimí en el Norte de Ấfrica en el año 296/909 representaba una seria amenaza política, militar y religiosa. Todo ello debió de influir en la suspicacia del emir 'Abd Alläh hacia su propia familia, de la que temía que algunos de sus miembros quisiesen destronarle como él había hecho con su propio hermano. El emir 'Abd Allāh no se limitó, en efecto, a ordenar la muerte de dos de sus hijos, también se le consideró responsable de la muerte de su hermano, el emir al-Mundir, y de otros hermanos suyos. La familia omeya parecía tan revuelta como revueltos eran los tiempos. El omeya Ibn al-Qitt encabezó en el año 288/901 una rebelión contra su pariente, el emir 'Abd Allāh, rebelión que tenía un fuerte contenido mesiánico y para la que pudo haber aprovechado las expectativas escatológicas difun-

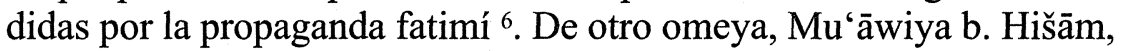
se dice que uno de sus hijos llevaba un peinado que se consideraba debían llevar tan sólo los hijos del emir que reinaba en ese momento, como si este $\mathrm{Mu}$ 'āwiya estuviese preparando a su hijo como candidato al trono ${ }^{7}$. Si ese hijo se llamaba 'Abd al-Raḥmān, ello habría sido

${ }^{6}$ Fierro, M., La heterodoxia, 106-111.

7 Ibid., 101, nota 16, donde remito a R. P. Dozy, «Introduction au Bayān», en Histoire de l'Afrique et de l'Espagne (ed. de al-Bayān al-mugrib), 2 vols, Leiden, 1848-1851, I, 55-6, quien a su vez remite a la Ihạta de Ibn al-Jatîib (v. ahora la edición de Muhammad 'Abd Allāh 'Inān , 4 vols., El Cairo, 1973-77, III, 280). El peinado consistía en llevar «une boucle de cheveux sur chaque côté du front» (trad. R. Dozy), es decir, un mechón $\left(\underline{d} u^{\prime} a b a\right)$ de pelo sobre cada lado de la frente. Este peinado recuerda al que se atribuye a 'Abd al-Rahmān I, quien llevaba dos trenzas (dafíra) (v. Dikr bilād al-Andalus, I, 108 y II, 117). Un reciente trabajo de Salvador Peña y Miguel Vega sobre la figura de Alejandro Magno / Dū l-Qarnayn («el de los dos cuernos») en monedas andalusíes («Who is the «warrion» on Western Islamic copper coins?», en curso de publicación) me hace pensar 
significativo, pues el nombre «'Abd al-Rahmān b. Mu'āwiya» (como vamos a ver en seguida) era el de 'Abd al-Raḥmān I.

Por lo que se refiere a 'Abd al-Raḥmān III, éste se apoyó en miembros de su familia en la primera parte de su reinado ${ }^{8}$, como veremos. Por su parte, Ibn Hazm afirma que expulsó a una tía suya, hermana de Mutarrif, del alcázar y que ésta encontró refugio con Mūsà b. Muhammad b. Hudayr, miembro de una importante familia de notables cordobeses, servidores de los omeyas. Este Mūsà era el prefecto de la ciudad (sāhib al-madīna) cuando 'Abd al-Raḥmān III fue nombrado emir y continuó ocupando altos cargos en años sucesivos ${ }^{9}$. Ibn Ḥazm nos dice que Mūsà había sido amigo íntimo de Muṭarrif (el asesino del padre de 'Abd al-Raḥmān III) y que, a pesar de ello, el nuevo emir le mostró amistad y utilizó sus servicios en la administración ${ }^{10}$. 'Abd al-Raḥmān III parece, pues, haber estado dispuesto a poner límites a su odio por el asesino de su padre.

Volviendo a las posibilidades que he planteado sobre la kunya de 'Abd al-Rahmmān III, ninguna se fundamenta en lo que sabemos sobre el uso y función de la kunya en el sistema onomástico árabe, es decir, no conozco ningún ejemplo que indique que la kunya se utilizase para reflejar esas o parecidas reacciones ${ }^{11}$.

El uso simbólico de la kunya Abū l-Muțarrif tiene otra explicación más convincente y es que se trata de la que había sido llevada antes por el fundador de la dinastía omeya en al-Andalus, el primer 'Abd al-Raḥmān (r. 138/756-172/788), llamado Abū 1-Muṭarrif 'Abd al-Raḥmān b. Mu'āwiya ${ }^{12}$. También fue llevada por 'Abd al-Raḥmān

en la posibilidad de que ese tipo de peinado pudiese sugerir una asimilación con ese personaje legendario que ocupa un lugar importante en el imaginario político-religioso musulmán.

${ }^{8}$ Aunque él también acabará ordenando la muerte de algunos parientes, como su tío al-'Āṣī y su primo Muhammad b. 'Abd al-Ŷabbār, a los que ordenó ejecutar en 309/921 acusados de conspiración. En el año 338/950 tuvo lugar la ejecución de uno de los hijos de 'Abd al-Rahmān III, 'Abd Allāh.

${ }^{9}$ Sobre este Ibn Hudayr y su familia, véase Meouak, M., Pouvoir souverain, administration centrale et élites politiques dans l'Espagne umayyade (IIe-Ve/VIIIe-Xe siècles), Helsinki, 1999, 117-128.

10 Ibn Hazm, Naqt, 173/132.

11 Sobre el uso y valor de la kunya, véase Goldziher, I., Muslim Studies, trad. de S. M. Stern, 2 vols., Londres, 1967-1971, I, 242; EI $^{2}$, s.v. kunya (A. J. Wensinck); Sublet, J., Le voile du nom: essai sur le nom propre arabe, París, 1991, 39-78.

${ }_{12}$ Meouak, M., «Notes sur les titres, les surnoms et les kunya-s du premier émir hispano-umayyade 'Abd al-Raḥmān b. Mu'āwiya», Al-Qanțara XII (1991), 353-70. Véase 
II (r. 206/822-236/852), llamado Abū 1-Muṭarrif 'Abd al-Raḥmān b. al-Hakam, cuarto emir de la dinastía y responsable del aggiornamento de los omeyas mediante la asimilación de las prácticas 'abbasíes de gobierno y de su cultura cortesana, así como mediante un decidido apoyo al desarrollo del grupo de los ulemas; en otras palabras, un emir considerado como una especie de re-fundador de la dinastía. Con estos precedentes no es de extrañar que el nombre 'Abd al-Raḥmān, que para algunos autores se transformó en el nombre por antonomasia de los emires omeyas andalusíes ${ }^{13}$, fuese asociado en dicha familia a la kunya Abū l-Mutarrif ${ }^{14}$. Ésta, pues, unida al ism 'alam 'Abd al-Raḥmān sirve para indicar que el omeya que lleva ese nombre se llama como el fundador de la dinastía.

Pero, ¿hasta dónde llegó la similitud entre 'Abd al-Raḥmān III y su antepasado 'Abd al-Raḥmān I? ¿Y quién o quiénes fomentaron esa similitud?

La elección de 'Abd al-Raḥmān III como sucesor del emir 'Abd Allāh parece haber tenido lugar en vida de este último. Al menos así lo dejan entender las fuentes ${ }^{15}$, que narran cómo 'Abd Allāh había mostrado preferencia por su nieto al instalarlo con él en el alcázar, mientras que sus hijos no vivían allí con él. En algunas fiestas, 'Abd Allāh hizo que 'Abd al-Raḥmān se sentase en el trono para recibir los saludos del ejército y se dice que en su lecho de muerte, 'Abd Allāh dio su anillo a su nieto, lo cual era una forma de designarle como sucesor ${ }^{16}$. Esto se podría entender en el sentido de que mientras que 'Abd Allāh parece haber sentido una gran desconfianza hacia sus propios hijos, un nieto le debía parecer menos peligroso, pues al tener

también supra, lo dicho sobre el posible nombre del hijo de ese miembro de la familia omeya, Mu'āwiya b. Hišām, que se peinaba como lo hacían los hijos de los emires reinantes.

${ }^{13}$ Como el nombre Alfonso se transformó también en el nombre por antonomasia de los reyes cristianos de Asturias en las fuentes árabes.

${ }^{14} \mathrm{La}$ asociación de la kunya Abū l-Muțarrif con el nombre 'Abd al-Raḥmān parece haber sido un rasgo onomástico característico de la familia omeya, ya que no abunda en la onomástica de los ulemas andalusíes (donde el nombre 'Abd al-Raḥmān parece ir asociado sobre todo a las kunyas Abū l-Qāsim y Abū Zayd).

${ }^{15}$ Fuentes que, como tendremos ocasión de recordar, se compilan en época califal y en las que, por tanto, hay que suponer una predisposición - si no intención clara- de asentar la legitimidad de la sucesión del emir 'Abd Allāh en la persona de su nieto negando la existencia de otros candidatos.

${ }_{16}$ Crónica Anónima de al-Nāsirir, ed. y trad. É. Lévi-Provençal y E. García Gómez, Madrid-Granada, 1950, 28-9/91. 
menor edad podía controlarlo mejor y los altos dignatarios de la dinastía (ahl al-dawla) bien pudieron pensar lo mismo. También cabe la posibilidad de que se le eligiese porque se veía en él a alguien que podía hacer frente con mayores probabilidades de éxito a algunos de los peligros que amenazaban a la dinastía omeya y en este sentido parece ir el siguiente texto: «Los altos funcionarios del Estado tenían puestas en él sus esperanzas, seguros de que a él iría a parar la autoridad. Por ello, al morir su abuelo, lo hicieron ocupar su puesto en el Califato, con mengua de los propios hijos del difunto»" ${ }^{17}$.

El llamarse 'Abd al-Rahmān, aunque importante, como hemos visto, no era decisivo, pues el emir 'Abd Allāh tenía dos hijos llamados 'Abd al-Rahmān y no parece que se les considerase candidatos al trono (aunque cabe preguntarse si esta información habría sido recogida en las fuentes de que disponemos, compuestas en su mayor parte a partir del califato de 'Abd al-Raḥmān III, cuya legitimidad exaltan). Si no lo fueron, una de las causas pudo ser la edad. 'Abd al-Raḥmān I tenía entre 24 y 25 años solares años cuando se convirtió en el primer emir de al-Andalus ${ }^{18}$. Un nuevo 'Abd al-Raḥmān no podía ser una persona mayor ${ }^{19}$. Pero dada la estructura de la familia musulmana, esos hijos del emir 'Abd Allāh llamados 'Abd al-Raḥmān pudieron tener la misma edad que su sobrino. Si se eligió a este último, pudo deberse entonces no sólo a que se le podía presentar como un nuevo 'Abd al-Rahmān, sino a que había dado pruebas de las aptitudes necesarias para el gobierno y para asegurar la supervivencia de la dinastía. Hay, sin embargo, otro factor a tener en cuenta que hacía necesario que el nuevo 'Abd al-Raḥmān fuese el nieto, no el hijo, del emir reinante.

'Abd al-Raḥmān III llegó al trono sin ser hijo del emir anterior. Hasta entonces, la sucesión dentro de la familia omeya había sido de

17 Crónica Anónima, 29/91. En un reciente estudio (Manzano, E., «El círculo de poder de los califas omeyas de Córdoba», Cuadernos de Madinat al-Zahrā' 5 (2004), 9-29, 14-5) se plantea la posibilidad de que en la designación de 'Abd al-Rahmān III jugaran un papel importante intrigas palaciegas desarrolladas cuando su anciano abuelo aún se encontraba moribundo, para lo que parece basarse en este texto. Veremos a continuación qué es lo que podía esconderse en esa actitud de los altos funcionarios.

18 'Abd al-Rahmān I nació en el 112 o 113/730-732 y fue proclamado emir en el año 138/756. 'Abd al-Raḥmān III nació en 277/890-1 y cuando subió al trono en 300/912 tenía 21 años solares.

19 Véase el mismo problema de la edad en la identificación del primer califa fatimí con el Mahdī Muhammad b. Ismā‘īl: Halm, H., The Empire of the Mahdi: The Rise of the Fatimids, trad. M. Bonner, Leiden, 1996, 159-160. 
padres a hijos ${ }^{20}$. La única excepción hasta entonces era la sucesión del emir al-Mundir (r. 273/886-275/888). Éste había sucedido al emir Muhammad (r. 238/852-273/886), pero su temprana muerte fue aprovechada por su hermano 'Abd Allāh, su probable asesino y abuelo de 'Abd al-Raḥmān III, para sucederle. Además de Muḥammad y Muțarrif, los hijos a los que el emir 'Abd Allāh hizo matar, éste, como ya he indicado, tenía otros hijos ${ }^{21}$, algunos de los cuales, como al-'Āṣi y Abān, tenían amplia experiencia militar y política, por lo que habría sido de esperar que hubiesen sido considerados como candidatos a suceder a su padre en circunstancias normales. Que éstas no lo eran se mostraría en el hecho de que las fuentes insisten en que los tíos paternos de 'Abd al-Raḥmān III no se opusieron a la elección de este último como emir, antes bien, parecen haberla apoyado como la mejor opción. Esta falta de oposición por parte de los parientes de mayor edad de "Abd al-Raḥmān III es algo que las crónicas señalan como si fuera algo digno de ser reseñado. Recuérdese ese texto de la Crónica Anónima en la que se dice que altos dignatarios de la corte apoyaron a 'Abd al-Rahmmān III al morir su abuelo «con mengua de los propios hijos del difunto», para luego mostrar a esos hijos, tíos paternos de 'Abd al-Raḥmān III, asistiendo a la ceremonia en la que fue proclamado emir y pronunciando el juramento de obediencia, sin que se diga que mostraran reserva alguna. Un hermano del difunto emir 'Abd Allāh es mencionado incluso dando gracias a Dios en aquella ocasión por haber elegido como emir a 'Abd al-Raḥmān ${ }^{22}$.

Pues bien, la razón de que se eligiese a un nieto y no a un hijo del emir 'Abd Allāh tuvo que ver nuevamente con la búsqueda de una similitud con la figura de 'Abd al-Rahmmān I. Y es que el padre de 'Abd al-Raḥmān I, Mu'āwiya b. Hišām b. 'Abd al-Malik b. Marwān, no llegó a reinar (nombrado heredero, murió prematuramente), mientras que su abuelo fue el califa omeya de Damasco Hišām (r. 105/724-125/743). 'Abd al-Raḥmān I fue, por tanto, nieto, no hijo, de

\footnotetext{
${ }^{20}$ El hijo que sucedía al emir anterior no era necesariamente el primogénito, si bien parece haber habido una tendencia hacia la primogenitura: véase Manzano, E., «El círculo de poder de los califas omeyas de Córdoba», 11-15.

21 Véase Uzquiza, A., «La familia omeya en al-Andalus», Estudios onomástico-biográficos de al-Andalus. V. Familias andalusies, ed. M. Marín y J. Zanón, Madrid, 1992, 373-432.

22 Ya he mencionado en la nota 8 que uno de esos tíos fue ejecutado en 309/921, lo cual parece indicar que sí debió haber reservas.
} 
califa, punto éste que ya fue subrayado por Martínez-Gros ${ }^{23}$. Un nuevo 'Abd al-Raḥmān debía parecérsele en esto también, como ocurrió con 'Abd al-Rahmān III, cuyo padre no reinó y que sucedió a su abuelo ${ }^{24}$. De 'Abd al-Rahmān I se decía que había sido el favorito de su abuelo, el califa omeya de Damasco Hišām ${ }^{25}$, como 'Abd al-Raḥmān III lo fue de su propio abuelo, el emir 'Abd Allāh. A partir de esta similitud (que es la que pudo motivar esas «esperanzas» de los altos funcionarios del Estado), sobre la figura de 'Abd al-Raḥmān III se fueron acumulando (sin duda intencionadamente) otros elementos que reforzaban la asimilación a la figura de su antepasado, el fundador de la dinastía. Así, tenemos el hecho de que el colaborador más próximo a 'Abd al-Rahmmān III en la primera parte de su reinado se llamase Badr ${ }^{26}$, pues el éxito de 'Abd al-Raḥmān I en al-Andalus se debió en gran medida a la energía y devoción de su esclavo manumitido Badr. Los sirios del ŷund de Damasco fueron los primeros en reconocer la autoridad de 'Abd al-Raḥmān I tras su desembarco en Almuñécar. Por su parte, 'Abd al-Raḥmān III, al poco de subir al trono, obtuvo el apoyo del ŷund de Damasco para iniciar la pacificación de al-Andalus ${ }^{27}$. En algunas fuentes se dice explicitamente que reconquistó al-Andalus como su antepasado 'Abd al-Raḥmān I lo había

\footnotetext{
${ }^{23}$ Martínez-Gros, G., L'idéologie omeyyade, 115. Independientemente de esta cita, tuve ocasión de discutir esa coincidencia de la sucesión «abuelo-nieto» con Manuela Marín, a quien agradezco sus sugerencias.

${ }^{24} \mathrm{Ibn}$ Hazm, Naqt, 81/104, afirma que sólo un califa, 'Abd al-Rahmān III, sucedió a su abuelo, ya que 'Abd al-Raḥmān I nunca llevó el título de califa.

25 Anderson, C., «Identity and the transplanted dynasty. The country estates of Umayyad Córdoba», Chicago Art Journal 13 (2003), 33-45, 35, señala que fue en la residencia palaciega de al-Rușāfa, en Siria, donde el califa omeya Hišām habría reconocido la futura importancia de su nieto. Como es sabido, 'Abd al-Rahmān I ordenó construir cerca de Córdoba una residencia palaciega con el mismo nombre, que el joven 'Abd al-Raḥmān III visitó varias veces en compañía de su abuelo 'Abd Allăh. Sobre esto último, v. EI ${ }^{2}$, s.v. «Rușāfa. In Muslim Spain» (M. Marín).

${ }^{26}$ Éste era un niño abandonado al que se encontró en los jardines del palacio real y del que se encargó Aḥmad, hijo del emir 'Abd Allāh (de ahí su nombre Badr b. Aḥmad). Se le presenta como cliente omeya, como si se tratase de un esclavo manumitido. Sobre el confuso estatuto legal de los niños abandonados (a los que a veces se esclavizaba), véase Schneider, I., Kinderverkauf und Schuldknechtschaft. Untersuchungen zur frühen Phase des islamischen Rechts, Stuttgart, 1999. La analogía entre los dos Badr ha sido señalada anteriormente: Fierro, M.I., «Sobre la adopción del título califal por 'Abd al-Rahmān III», Sharq al-Andalus VI (1989), 33-42, 36 (nota 22) y 38; Martínez-Gros, G., L'idéologie omeyyade, 127.

${ }^{27}$ Crónica Anónima, 34/97. Este episodio está tan marcado por el paralelismo que se quiere establecer con la peripecia vital de 'Abd al-Rahmān I que hay que cuestionarse hasta qué punto esa referencia al $\hat{y} u n d$ de Damasco responde a la realidad.
} 
conquistado ${ }^{28}$. E. Manzano me indica que el hijo primogénito de 'Abd al-Rahmān III, que posiblemente estuvo llamado a sucederle y que, sin embargo, murió prematuramente, se llamó Hišām, el mismo nombre que ostentó el sucesor del fundador de la dinastía.

¿Por qué era importante que el emir que tenía que suceder a 'Abd Allāh se presentase como un nuevo 'Abd al-Raḥmān I? Cuando 'Abd al-Raḥmān III se proclamó califa, mencionó unas predicciones que circulaban sobre él. En esas predicciones, que no se han conservado, pudo reflejarse el hecho de que su nombre coincidía con el del fundador de la dinastía y con el de 'Abd al-Raḥmān II. Es decir, que pudo capitalizar a su favor el papel sobresaliente que habían jugado los dos antecesores que llevaban su mismo nombre. Pero hay otro elemento a tener en cuenta y es que 'Abd al-Raḥmān III era el octavo omeya en subir al trono. Este número se destaca en un poema, donde se hace referencia a él como «octavo de los califas que vivieron» ${ }^{29}$, y también en un documento contemporáneo, la carta de Ḥasdāy $b$. Šaprūt a los Jazares, donde se menciona a 'Abd al-Raḥmān III como 'Abd al-Raḥmān VIII ${ }^{30}$. Es decir, 'Abd al-Raḥmān III accedía al trono después de que hubiesen gobernado siete omeyas. El simbolismo del número siete en el mundo islámico es bien conocido ${ }^{31}$. Para el caso concreto de los omeyas, los califas de Damasco habían sido catorce, siendo el séptimo Sulaymān b. 'Abd al-Malik (r. 96/715-99/717), bajo cuyo gobierno culminó la conquista musulmana de al-Andalus. El califa octavo fue 'Umar (II) b. 'Abd al-'Azīz, cuyo gobierno coincidió con el cambio de siglo de la hégira (r. 99/717-101/720) y que de todos los omeyas es el que gozó de una mejor reputación religiosa, considerándosele un renovador religioso ${ }^{32}$. A estos dos ciclos de

${ }^{28}$ Dikr bilād al-Andalus, 132-3/170-1 (cf. Ibn 'Iḍārī, Bayān, II, 157, donde se dice que 'Abd al-Raḥmān III se parecía a 'Abd al-Raḥmān I), citas ya señaladas en Fierro, M.I., «Sobre la adopción», 36. V. también Martínez-Gros, G., L'idéologie omeyyade, 113-128.

${ }^{29}$ Ibn Hayyān, Muqtabis $V, 31 / 49$.

${ }^{30}$ Del Valle Rodríguez, C., La Escuela Hebrea de Córdoba. Los origenes de la Escuela filológica de Córdoba, Madrid, 1981, 319-58. Del Valle no entiende esta referencia a al-tämin e intenta explicarla, diciendo que posiblemente se trata de un error de escriba y que quizá subyace la hebraización de la palabra al-šāmī, el sirio (p. 335, nota 41). Pero es evidente que el texto dice que era el octavo gobernante omeya.

${ }^{31}$ Conrad, L., «Seven and the tasbi $i^{`}$ : On the Implications of Numerical Symbolism for the Study of Medieval Islamic History», Journal of the Economic and Social History of the Orient XXXI, 42-73.

${ }^{32}$ Landau-Tasseron, E., "The 'cyclical-reform': a study of the mujaddid tradition", Studia Islamica LXX (1989), 79-118, 84. 
siete califas omeyas, cortados por el cambio del s. I al II de la hégira, había sucedido el ciclo de siete emires omeyas de al-Andalus, que venía a terminar precisamente en otro cambio de siglo, el del s. III al IV de la hégira. El reino del emir 'Abd Allāh (m. muy apropiadamente en el año 300/912 ${ }^{33}$ ) representaba, pues, no sólo el final de un ciclo de siete emires omeyas en al-Andalus, sino que también estaba próximo a un cambio de siglo. En este contexto, bien pudo empezar a circular la idea de que era el momento de que apareciese entre los omeyas un nuevo 'Abd al-Rahmān que, como el primero que había escapado de Oriente a la caída de la dinastía omeya de Damasco logrando volver a levantar la fortuna de la familia, abriese un nuevo ciclo de poder y prosperidad para la dinastía. De ahí que me incline por pensar que la decisión de elegir a un nieto, y no a un hijo del emir reinante, y que ése llevase el nombre y la kunya del primer "Abd al-Raḥmān, debió tomarse (o al menos discutirse seriamente) en los círculos cortesanos durante el reinado de 'Abd Allāh.

El ciclo basado en el número siete no se limitaba a la familia omeya ${ }^{34}$. Tenía una importancia muy superior en la doctrina ismā'îlí de los califas fatimíes y éstos se contaban entre los rivales más peligrosos a los que los omeyas tenían que hacer frente en los últimos decenios del s. III/IX. De hecho, por causa de los fatimíes, 'Abd al-Rahmān III se decidiría a dar un paso, la adopción del título califal, al que sus antepasados no se habían atrevido. Los omeyas, llegados al poder en al-Andalus tras escapar 'Abd al-Rahmān I de la masacre de los 'abbasíes, no se proclamaron califas para mostrar su rechazo a los 'abbasíes y a pesar de considerar a éstos usurpadores de lo que legítimamente les correspondía ${ }^{35}$. Pero ahora, los fatimíes establecían un nuevo califato cerca, muy cerca de al-Andalus, y además lo hacían

${ }^{33} \mathrm{La}$ fecha parece demasiado apropiada como para ser casual, pero las fuentes no dejan entrever en ningún momento la posibilidad de que el fallecimiento del emir 'Abd Allāh fuese adelantado para coincidir con el año de cambio de siglo, el año además en el que los ismā'īlíes esperaban la aparición del Mahdī.

${ }^{34} \mathrm{El}$ «profeta» beréber Sāaliḥ al-Bargawāṭi profetizó que él volvería cuando el séptimo jefe de los Bargawāța hubiese alcanzado el poder: Fierro, Heterodoxia, 30.

35 Veánse Fierro, M. I., «Sobre la adopción del título califal»; Safran, J., The Second Umayyad Caliphate. The articulation of caliphal legitimacy in al-Andalus, Cambridge, Mass. / Londres, 2000. Ibn Hazm, en su Naqt al-'arūs, afirma que 'Abd al-Raḥmān III pasó de emir a califa por designación de una asamblea (̌̌ūrà). Ésta era la única fórmula que podía asignarle ya que las otras dos fórmulas (nombramiento de heredero o golpe de fuerza) no eran posibles: v. Fierro, «Sobre la adopción del título califal», p. 38. Ibn Hazm no se refiere en ese texto a còmo sucedió 'Abd al-Raḥmān a su abuelo 'Abd Allāh. 
como herejes. Los fatimíes pertenecían a la rama ismā'îlí del šīísmo, que sostenía que los imames, vicarios de Dios en la tierra, se suceden en ciclos de siete, como los días de la semana ${ }^{36}$. Para ellos, además, el séptimo imām del ciclo islámico, su antepasado Muhammad b. Ismā‘īil, era el Mesías (al-Mahdī), cuyo regreso había sido predicho para el año 300/912-3 ${ }^{37}$, es decir, en el mismo año en que 'Abd al-Rahmmān III se convirtió en emir. Además de esta posible influencia del simbolismo del número siete y de otras formas en las que el establecimiento del califato fatimí influyó en diversos aspectos de la actividad de 'Abd al-Raḥmān III ${ }^{38}$, el matrimonio de 'Abd al-Raḥmān III con una pariente suya, hija de su tío abuelo al-Mundir, también pudo ir en el mismo sentido. Ese matrimonio, que pudo producirse cuando ya era emir, servía sin duda para intentar contentar a una rama de la familia que había sufrido a manos de 'Abd Allāh, pero es que el nombre de esa mujer (la única qurayší con la que parece haber casado 'Abd al-Raḥmān III) era Fātima.

La asociación del cambio de siglo con expectativas mesiánicas y el establecimiento del califato fatimí por medio de un hombre llegado de Oriente que lograba hacerse con el poder en Occidente (siguiendo el mismo modelo de 'Abd al-Raḥmān I y también el del fundador de la dinastía idrisí en el Magreb ${ }^{39}$ ) influyeron también en la trayectoria de Ibn Hafṣūn (m. 305/918), como ya tuve ocasión de poner de relieve en otra ocasión ${ }^{40}$, al mostrar que determinados episodios de la biografía del rebelde muladí debían ser interpretados como una «recreación» de la biografía de 'Abd al-Raḥmān I. En la biografía del primer

\footnotetext{
${ }^{36}$ Halm, H., Empire, 17-22; $E I^{2}$, s.v. Ismā'īliyya (W. Madelung), especialmente 204. Véase también Corbin, H., La paradoja del monoteismo, trad. M. Tabuyo y A. López, Barcelona, 2003, 139 y ss. y del mismo autor, Tiempo cíclico y gnosis ismailí, Madrid, 2003 (debo estas referencias a Salvador Peña).

37 Crone, P. y Treadwell, L., «A new text on Ismailism at the Samanid court», Texts, documents and artefacts. Islamic Studies in honour of D.S. Richards, ed. Ch. Robinson, Leiden / Boston, 2003, 37-67, 60.

38 Pueden verse M. Fierro, «La política religiosa de 'Abd al-Raḥmān III», Al-Qantara XXV (2004), 119-156 y «Madinat al-zahrā', el Paraíso y los fatimíes», Al-Qantara XXV (2004), 299-327.

39 Este modelo y sus implicaciones han sido tratados por Martínez-Gros, G., «Le passage vers l'Ouest. Remarques sur le récit fondateur des dynasties Omeyyade de Cordoue et Idrisside de Fès», Al-Masāq 8 (1995), 21-44.

40 «Cuatro preguntas en torno a Ibn Hafșūn», Al-Qanțara XVI (1995), 221-257, 253-4; trad. inglesa en The Formation of al-Andalus. Part 1: History and Society, ed. M. Marín, Ashgate, 1998, The formation of the classical Islamic world, vol. 46, 291-328
} 
emir omeya, como en la de Ibn Hafșūn, hay una predicción que les asegura que llegarán a gobernar, además ambos personajes residen un tiempo en Tāhert y ambos cruzan el Estrecho para dominar al-Andalus. Con todo ello, se establece un claro paralelismo con la trayectoria de 'Abd al-Raḥmān I, el fundador de una dinastía, que era lo que Ibn Hafșūn aspiraba a ser.

Esta idea ha sido complementada por D. Wasserstein en su estudio sobre la (falsa) cadena genealógica de Ibn Hafṣūn ${ }^{41}$, la cual consta de siete eslabones (incluyendo a 'Umar) y que viene a terminar en un Adfunš o Alfonso. Creo que la elección de este último nombre no fue casual. En el territorio cristiano de la Península, no se era tampoco ajeno a la necesidad de un rey renovador, papel que recayó en la figura de Alfonso III (r. 866-910), continuador de la política de expansión en tierras musulmanas y bajo cuyo gobierno se formula una ideología justificadora de las conquistas. Fue entonces cuando se desarrolló una importante producción cronística en la que se afirmaba que el reino astur era el heredero del reino visigodo de Toledo y que la lucha contra los musulmanes era una reconquista o recuperación de lo perdido ${ }^{42}$. Zamora, conquistada por los cristianos en 893 , se convertirá en la meta del ejército levantado por el rebelde omeya Ibn al-Qitț que se había proclamado el Mahdī o Mesías. En época de Alfonso III se escribe la llamada Crónica Profética que alude a profecías que indican el fin del dominio árabe en la Península, en un clima de expectaciones escatológicas y mesiánicas sobre el que hay abundante información ${ }^{43}$.

Alfonso III, como 'Abd al-Raḥmān III, era el tercero de su nombre. Alfonso I (r. 739-757), de quien se especifica que tenía linaje regio, es presentado como el artífice de numerosas conquistas y de haber infligido numerosas derrotas a los musulmanes ${ }^{44}$. Le siguió

${ }^{41}$ «Inventing tradition and constructing identity: the genealogy of 'Umar ibn Hafsūn between Christianity and Islam», Al-Qantara XXIII (2002), 269-298.

42 Véase el reciente análisis de Escalona, J., «Family memories: inventing Alfonso I of Asturias», Building Legitimacy: political discourses and forms of legitimation in Medieval societies, ed. I. Alfonso, H. Kennedy y J. Escalona, Leiden, 2004, 223-262, donde se cita la bibliografía relevante. No he podido consultar Deswarte, T., De la destruction à la restauration. L'idéologie du royaume d'Oviedo-León (VIIIe-XIe siècles), Turnhout, 2003.

43 Gil, J., «Judíos y cristianos en Hispania (s. VIII y IX)», Hispania Sacra XXXI (1978-1979), 9-80.

${ }^{4}$ El ensalzamiento de su figura (se le llega a atribuir un milagro) tal vez refleje su papel como contrapunto de 'Abd al-Raḥmān I, proclamado emir independiente en el año 
Alfonso II (r. 791-842), bajo cuyo reinado creció la influencia carolingia (como se produjo la 'abbāsí en época de 'Abd al-Rahmān II). En las crónicas que se escribieron bajo el reinado de Alfonso III, es sobre todo la figura de Alfonso I la que adquiere una gran importancia, tal y como ha mostrado Julio Escalona, en tanto que se convierte en la encrucijada de una serie de discursos legitimadores con los que se buscaba sustentar el goticismo de la línea dinástica reinante ${ }^{45}$.

En las últimas décadas del s. III/IX omeyas, fatimíes y astures estuvieron todos ocupados, y al mismo tiempo, en remontar a sus orígenes la legitimidad del presente. En época del emir 'Abd Allāh (posiblemente a instigación suya y apoyado por esas familias de clientes omeyas que ocupaban altos puestos en la administración y que tanto interés tenían en la supervivencia de la dinastía), parece haberse puesto en marcha un proyecto de sucesión que asegurase que el nuevo emir fuese 'Abd al-Raḥmān III, pues en tanto que convincente re-encarnación del fundador de la dinastía omeya (nombre, juventud, nieto - que no hijo - del emir anterior), permitía hacer de él una figura predestinada a reinar frente a posibles rivales dentro de la familia omeya (recuérdese que ésta andaba desunida y revuelta) y además le dotaba de características de corte «mesiánico» para rivalizar con las pretensiones fatimíes. El primer califa fatimí, llamado al-Mahdī (r. 297/910-323/934), sometió a varias manipulaciones tanto su nombre como el de su hijo para poder hacer creíble su descendencia del séptimo imām ismā'îlí y también para alargar el cumplimiento de las expectativas mesiánicas que el establecimiento del califato fatimí había despertado ${ }^{46}$. Alfonso III «inventa» a Alfonso I para legitimar la nueva ideología política, el goticismo, del reino astur. Es en este contexto en el que se entiende que Ibn Ḥaf̣ūn — que tantas teclas tocó buscando (infructuosamente) una legitimidad política que respaldase el poder adquirido-, en una de esas búsquedas de un fundamento firme en el que apoyarse, necesitase también un Alfonso en su cadena genealógica.

138/756. Sobre el posible «juego de espejos» que se dio en la legitimación dinástica de omeyas y reyes astures, volveré en otra ocasión.

45 Véase el artículo de Escalona, J., citado en la nota 42

${ }^{46}$ Halm, H., Empire, 154-9. 